\title{
Trans-Tasman perspectives on transparency in decision-making: A view from Australia
}

\section{Anne Tiernan}

It is widely asserted that Australia's political culture is broken: that we have lost the capacity for long-term thinking, and are unwilling and unable to embrace necessary reform. In his contribution to this volume, Oliver Hartwich (Chapter 6) points out that Paul Kelly and other members of the Australian media share this view, and contrast current experience with a generally more successful past. Australians, I think, increasingly look to New Zealand for its more successful recent record of innovation and reform. How did it come to this? We have long since become accustomed to being outperformed on the rugby field, but that it has extended to governance has made us all uneasy.

My contribution to this volume is informed by two ANZSOG-funded research projects: one on prime ministers' chiefs of staff (Rhodes and Tiernan 2014), and one on examining the dynamics of central executives in four Westminster-style countries-Australia, Canada, New Zealand and the UK (Rhodes and Tiernan forthcoming). We have also developed cases from Queensland and Victoria to provide a subnational and a federal comparison. 
These projects provide a unique contemporary insight into the working dynamics of decision and advisory systems - those networks at the very centre of government. They also highlight some themes that are relevant, I think, to this volume's focus on transparency and engagement. The primacy of coping and survival in the calculus of political administrative elites, for example, cannot be overstated and is evident in all four countries. While efforts to address fragmentation and project coherence across policy and politics are ubiquitous, this seems to be a quest with neither end nor likely success. The current trend across all types of political systems is a push to centralisation and small group decision-making. This is creating myriad problems.

Comparisons between Australia and New Zealand often claim that reform is easier to undertake in New Zealand because it is not a federal system. I am very heartened that Oliver Hartwich did not claim this in his chapter. We should acknowledge that the unitary parliament, mixedmember proportional (MMP) electoral system of New Zealand places a powerful constraint on executive leaders in Wellington. I am persuaded that the MMP has an impact on political culture. I am less persuaded by the federalism argument. A lack of checks and balances has, at times, for example, led New Zealand to implement some horrible policies, particularly in housing regulation and others.

But I do think former prime minister John Key was an extremely interesting case study. Moreover, I think trade exposure and a much more existential experience of economic uncertainty has focused New Zealanders' minds on reform in a way that the mining boom maybe insulated Australians from doing. And yet, I think there is something generational about John Key and his deputy (later prime minister) Bill English that I think is very interesting. I would have put former NSW premier Mike Baird in the same category. And maybe in New Zealand it is an issue of scale, but I think there is also an interesting point to be made about that country in regards to career politics.

I suggest that the broken political culture-seen prominently in its difficulty to enact reform - is it least partly the result of structural problems. They are embedded in, and an unintended consequence of, successive waves of reform and change within the Australian core executive over the past 40 years. And I argue that ministers-particularly prime ministershave driven many of those changes but, taken together, those actions and 
decisions have undermined both the quality of advice and support that is available to them (in terms of routines and processes that provided advice and options), and the opportunities to consider it, debate and contest it.

Lest anyone think I am verballing any particular leader, I would note that questions about the performance of prime minsters' and premiers' offices have featured in the reviews into the defeats of the Napthine and Newman governments, both one-term governments; and the challenge to Tony Abbott's leadership in February 2015 and September of that year, when he eventually lost it. The same was true of Kevin Rudd and Julia Gillard, as Rod and I explore at length in our books.

It is not accidental, I think, that we are seeing profound loss of trust in the capacity and integrity of our political processes and institutions. One need only consider the social media response to revelations Bronwyn Bishop took a tax payer-funded helicopter flight from Melbourne to Geelong - since dubbed 'Choppergate'. This sentiment is also evident in opinion polling and, I think, quite starkly in the recent defeat of two first-term governments in Victoria and Queensland. And yet, it seems, politicians do not learn.

This is a real challenge, and I think there is a structural reason why it is happening. I also think it is significant that in August 2015, two Australian national newspapers (The Australian and The Australian Financial Review) hosted a National Reform Summit that specifically excluded politicians. Such engagement across sectors sent the message that organisers felt there was no point having the political parties at the table, since neither would engage in serious debate about reform. Perversely, leaders respond to that kind of pressure and complexity by turning inwards. They retreat to everdiminishing circles of close advisers and supporters.

Of course, it is extremely difficult to get on the front foot. Nobody knows that better than me, having spent much time around ministers and prime ministers. But being informed and prepared about the dynamics of leadership - the constraints and contingencies as well the opportunitiescan, I think, help immensely.

You do not achieve that by systematically undermining the institutional memory and your capacity to learn from experience in the systems of advice that support decision-making. Because of this, we can see the limits of centralisation and the lack of openness and transparency often associated with it. Problems are constantly exposed through the lack of 
coordination and coherence across the ministry and government-take 'captain's picks', a new term that has entered the political lexicon. Poor communication and sequencing of decisions compound the situation, as does a cabinet process whereby major issues are introduced 'under the line' only to be leaked, creating policy reversals in the face of apparently unexpected resistance. That is simply bad process and poor governance practice.

How have we ended up in this situation? I think there are fundamental questions to ask. Transparency is important but, for me, we are reaching a point where capacity and effectiveness have become the key questions. And yet, leaders seem either unable or unwilling to recognise themor they are so locked in their own path dependencies that they cannot recognise the underlying structural cause of their difficulties is them.

My chapter will focus on the impediments to reform and change that I think are inherent to the hybrid advisory system it has developed. New Zealand is nowhere near as far down this path as is Australia. Australia is at one kind of extreme. Queensland's a little further along that spectrum of hybridisation and expectations of political responsiveness; Victoria is somewhat less so. And then we have New Zealand and the UK at the other end. Our fieldwork revealed that Canada had shifted much more towards the hybrid model than I had expected.

What then are the impediments to reform and change? I have identified three: the loss of institutional memory; the associated failure to learn from experience; and leaders' lack of organisational capacity.

I will now outline some potential reform directions, noting that they featured in the difficulties experienced by current and former prime ministers and premiers. I argue there are lessons to be learned from New Zealand, but I think too much of the debate in Australia is focused on the performance of the public service and not enough on the demand side of the relationship.

Overcoming some of the problems that I have raised would require the political class to both reform and change its modus operandi and be prepared to embrace arrangements and frameworks that support rather than undermine their capacity to set and maintain a focus on priorities. This also applies to their ability to control the political and policy agenda within the constraints of what you can do in a very unpredictable environment and their ability to negotiate and manage the many 
relationships, contingencies and dependencies that characterise life at the centre of government. They really do not seem to have understood how much the context has changed.

Readers would be aware that everywhere, leaders are reshaping their advisory systems to cope with common pressures. We have seen growth, institutionalisation, hybridisation and politicisation (a contested term, but in this context I mean the advent of partisan advisers). There is a blurring of the boundaries between partisan and non-partisan sources of advice. There has also been a significant growth in centralisation around leaders, as anybody who works in Commonwealth or state government will be able to tell you. Communication and issues management are becoming predominant, and bureaucratic routines of control and coordination are struggling to cope with system demands.

Recent Australian prime ministers, going back to the election of John Howard in 1996, have struggled to make a successful transition to the office. Howard, Rudd, Gillard and Abbott all faced trouble. Rudd was arguably more successful in his transition in the first 12 months, mostly because of the support of the leadership team, with John Faulkner playing an especially important role in as special minister of state. It is often forgotten that John Howard himself faced leadership speculation in 1997 after the travel rorts affair.

Remember that? There was something to be learnt from that, I would think. But Howard was never challenged for the prime ministership, the reason being that he subsequently learned lessons and made changes to deal with the difficulties and criticisms that he faced. The other three faced leadership challenges early in their terms. It has been an unprecedented period of leadership instability.

The problems leaders have in navigating the transition to office are often attributed to the pace and complexity of decision-making. This has been well described. But the recurrence of this under four successive prime ministers, and a number of premiers, means we need to ask ourselves further questions.

The work with chiefs of staff and the project I am currently undertaking has revealed significant concerns about institutional memory within the central executive. The problem is well understood in the presidential context but less so at the level of political leadership in Australia, where it is acute at both the state and Commonwealth levels. I have already 
outlined some of the drivers, but I think the major point to consider is that institutional memory is essential to the ability to learn from and avoid repeating the mistakes of your predecessors. That 'Choppergate' occurred on the same side of politics so damaged by the travel rorts affair of 1997 starkly illustrates how little has been learned.

Really, then, the problem of a lack of institutional memory is one of leaders' own making. It is a relatively recent development, and even if they may not be conscious of it, they are largely responsible for it. The decision to shift their main source of advice and support from the Department of Prime Minister and Cabinet and the Department of Premier and Cabinet into the prime minister's and premier's offices, respectively, has had profound consequences. In effect, the prime minister's office is now performing key coordinating tasks that were once the province of the public service, making the role of the chief of staff especially critical. And yet, most recent appointees to this role have had very little bureaucratic experience and very few networks on which to draw when they come into the job.

As we demonstrate in the book, the pathway into the job today differs from the way it was in the past. As does the way out: when central figures of the prime minister's office leave, the whole show must start over. I had a lot of trouble persuading my co-author Rod Rhodes that this was the case. He found it absolutely unbelievable. But, over time, we were able to empirically demonstrate that this was, in fact, so.

I think another problem is the contemporary hyper-partisanship of Australian politics and the consequential reflex to denigrate and smash the legacy of the people who you have just defeated. The dilemma here is that a new government spends its first two years in office dismantling their predecessor's agenda before they enact their own. I think this limits and inhibits the ability and willingness to learn.

There is no doubt that the hybrid advisory model that has evolved in Australia since the 1970s has given ministers greater responsiveness and political control. But it has not resolved the fundamental questions of competence and responsiveness. Ministers remain dependent on many things, including the public service. Therefore, the need to preserve institutional memory remains important. New Zealand does a much better job of preserving institutional memory in a systemic manner. 
The hybrid model has made it the responsibility of prime ministers to organise and manage the advisory system, instead of leaving that to people who know how to do it.

It has put a burden on political leaders they did not have before. I don't believe they have particular insight into that. One of the striking things revealed in our research everywhere, with the possible exception of New Zealand, has been an increasingly distant relationship with the public service. The centre of the central executive no longer regards the public service as central or even necessary to decision-making. From the public service's perspective, this makes just 'keeping in the loop' difficult, let alone adapting to the dilemmas this changing context provides, in terms of the ability to influence it.

And yet we still talk about public sector reform. There is, of course, the question of the contestability of more fluid advisory systems. But while it is good to have alternative sources of advice (and ministers think this is very important), there is a fundamental problem of institutional memory with ad hoc arrangements. Evert Lindquist $(1999,2007)$ has done some work on this in the past. It raises questions about where authority lies.

Organisational capacity is a concept drawn from the presidential studies literature (Burke 2000, 2009; Dickinson 1997; Dickinson and Lebo 2007; Greenstein 2004). In the American context, where you have a whole bunch of people moving out and a whole bunch of new people moving in to take over with each change in presidency, they really have to think about how they are going to operate the machinery of government. In Australia, until recently, we have not needed to think about such things. The public service provided administrative continuity to support changes of government.

In the Australian context, organisational capacity might include things like forging an effective team; recruiting an appropriately qualified chief of staff; making sure good people serve in the prime minister's or premier's office. It also requires being able to coordinate; work with others; develop effective relationships (across the ministry, say, or the party room); ensure quality advice is coming in; discipline the flow of advice and create effective arrangements; communicate the narrative; and try to coordinate what we all know is a very difficult set of arrangements to coordinate. But there are still many disciplines you can bring to bear; it's just that a career in politics doesn't necessarily prepare prime ministers to do that. 
Nor, frankly, do I think having to focus on such things is a very good use of their time or expertise. We need to have a different conversation with political leaders.

So what might be done? There is no going back to the model as it was before, despite the lamentations of some. This is because politicians won't allow it, but also because staffers do things that public servants shouldn't and can't do. However, I am interested in the reform agenda as being much more to do with what could be done to preserve institutional memory. I have some specific suggestions regarding this.

What we know is that there has been persistent resistance from Australian politicians-not just to reforming travel entitlements but also (on both sides) to attempts to become the focus for reform and change themselves. Sir Arthur Tange talked about this in the 1980s (Edwards 2006). It is very interesting. Leaders need to be persuaded that they are poorly served by their current arrangements and, for me, this is the next frontier. I am struck by the New Zealand experience on this: they have got responsiveness, but it is still heavily predicated on the role of the public service. This does not mean the public service has a monopoly or policy advice, or that ministers do not seek alternative points of view. But they are doing it in a way that still maintains a degree of institutional memory.

In this context, I was feeling a little depressed about how things are going in Australia. And yet, New Zealand is not above critique. Their ministers' critiques of public service advice is that it is not sufficiently citizeninformed. But whatever their frustrations, New Zealand ministers do seem to accept that the public service is important in terms of continuity and institutional memory.

To conclude, when it comes to transparency, what I think we really need to think about is how all these mechanics work at the centre of government. Currently, we know surprisingly little about it. The empirical work that has been done in this area is by myself and Rod Rhodes, and it's an area that needs further research. In other words, there is really no institutional memory to operate the very central parts of government. That is a frailty that worries me. I think we need to be debating this much more seriously; I think ministers need to stop being the elephant in the room of public sector reform and become part of it. 


\section{References}

Burke, J.P. 2000. The Institutional Presidency. 2nd edition. Baltimore: Johns Hopkins Press.

Burke, J.P. 2009. 'Organizational Structure and Presidential DecisionMaking'. In G.C. Edwards and W.G. Howell (eds), The Oxford Handbook of the American Presidency. New York: Oxford University Press, pp. 501-27.

Dickinson, M.J. 1997. Bitter Harvest: FDR, Presidential Power and the Growth of the Presidential Branch. Cambridge: Cambridge University Press.

Dickinson, M.J. and M. Lebo. 2007. 'Re-examining the Growth of the Institutional Presidency: 1940-2000'. The Journal of Politics 69(1): 206-19.

Edwards, P. 2006. Arthur Tange: Last of the Mandarins. Sydney: Allen \& Unwin.

Greenstein, F. 2004. The Presidential Difference: Leadership Style from FDR to George W. Bush. Second Edition. Princeton: Princeton University Press.

Lindquist, E. 1999. 'Reconceiving the Center: Leadership, Strategic Review and Coherence in Public Sector Reform'. Organisation for Economic Co-operation and Development. Available from www.oecd. org/officialdocuments/publicdisplaydocumentpdf/?cote=PUMA/ SGF(99)5\&docLanguage $=$ En

Lindquist, E. 2007. 'Organizing for Policy Implementation: The Emergence and Role of Implementation Units in Policy Design and Oversight'. Journal of Comparative Policy Analysis: Research and Practice 8(4): 311-24. doi.org/10.1080/13876980600970864

Rhodes, R. and A. Tiernan. 2014. The Gatekeepers: Lessons from Prime Ministers' Chiefs of Staff. Melbourne: Melbourne University Press.

Rhodes, R. and A. Tiernan. forthcoming. Ministers and their Courts: Evaluating Ministerial Support Systems.

Rhodes, R., J. Wanna and P. Weller. 2009. Comparing Westminster. Oxford: Oxford University Press. 
This text is taken from Opening Government: Transparency and Engagement in the Information Age, edited by John Wanna and Sam Vincent, published 2018 by ANU Press, The Australian National University, Canberra, Australia.

doi.org/10.22459/OG.04.2018.05 